\title{
COMUNICAÇÃO SIGILOSA DE SORODIAGNÓSTICO POSITIVO PARA HIV À GESTANTE PELA ENFERMEIRA OBSTÉTRICA
}

\section{CONFIDENTIALITY TEST OF POSITIVE FOR HIV TO PREGNANCY BY OBSTETRICAL NURSE}

\author{
Lucia Helena Garcia Penna, Michelle dos Santos Porto, Raquel de Souza Tavares, \\ Luiza Mara Correa, Fernanda Rodrigues C. Morais, Francislene de Souza Pace e \\ Aida de Souza Dutra \\ Universidade do Estado do Rio de Janeiro
}

\section{Resumo}

Identifica os sentimentos da enfermeira em relação à cliente e à comunicação do resultado positivo de exame sorológico para HIV e descrever as estratégias utilizadas pela mesma para comunicá-lo à gestante da forma mais sensível possível. Caracteriza-se como descritiva, exploratória qualitativa. Os sujeitos do estudo foram 10 enfermeiras obstétricas que tiveram alguma experiência em comunicar o resultado positivo de exame sorológico para HIV. Aplicou-se um questionário e utilizou-se a técnica de análise de conteúdo. As enfermeiras traçam condutas de forma a acolher a gestante e buscam atendê-la de forma integral, se preocupando também com o parceiro e a criança que está por vir. As estratégias utilizadas têm como referência a humanização, acolhimento, conhecimento sobre Aids e criação de rede de apoio. Observa-se ao comunicar o resultado a sensibilidade das enfermeiras perante as clientes, com aparecimento do sentimento de empatia e a dificuldade em comunicar o diagnóstico positivo para HIV.

Palavras Chaves; Comunicação Sigilosa, Sorodiagnóstico da AIDS, Gravidez e Enfermagem Obstétrica.

\begin{abstract}
Identify the feelings of nurses compared to the client and the reporting of a positive blood test for HIV and to describe the strategies used by it to notify the woman's most sensitive way possible. It is characterized as descriptive, exploratory qualitative. The study subjects were 10 midwives who have had some experience in communicating the positive result of testing for HIV. We applied a questionnaire and used the technique of content analysis. Nurses draw pipes to welcome the mother and seek answer it fully, they also focus on the partner and child to come. The strategies used by reference to the humanization, host, knowledge about AIDS and creating a network of support. Notes wishes to communicate the results of the sensitivity of nurses in the face of customers, with emergence of a feeling of empathy and the ability to communicate the positive diagnosis for HIV.
\end{abstract}

Keywords: Confidentiality, Serodiagnosis of AIDS, Pregnancy and Obstetrical Nursing. 


\section{INTRODUÇÃO}

No acompanhamento gestacional de baixo risco, geralmente a maternidade é percebida como o renascer de uma vida e, as relações interpessoais entre profissionais e cliente são estabelecidas nesse clima. Já na gestação que apresenta algum agravo há uma maior valorização deste em detrimento do próprio processo da maternidade. No caso da soropositividade para Hiv na gestação, o estigma histórico social sobre a Aids calcado em bases conceituais de "doença letal"; "mal do século", "a doença do pecado" e tantos outros, acabam interferindo nesse cenário de vida. Logo, é possível considerar que muitos são os profissionais que apresentam dificuldades, constrangimentos e mesmo se negam a querer comunicar tal resultado, principalmente em decorrência de tal estigma social que a Aids ainda representa, do receio em como a gestante irá reagir.

A Síndrome da Imunodeficiência Adquirida (Aids) tornou-se um grave problema de saúde pública no Brasil. Estima-se que cerca de 0,65 \% da população infectada pelo vírus $\mathrm{E}$ estudos apontam que da década de 80 até o final da década de 90, a epidemia cresceu nove vezes mais entre mulheres do que entre os homens (GALVÃO, 2003).

Ao observarmos o aumento considerável do número de casos de mulheres infectadas destacamos outra problemática que é o aumento dos casos de gestantes HIV positivas. Com uma prevalência de $0,41 \%$ de infecção pelo HIV em gestantes, estima-se que 12.456 recém-nascidos sejam expostos ao HIV por ano Entre 2000 e 2005, foram notificados 23.462 casos novos de gestantes HIV positivas no país (BRASIL, 2006).

Entende-se que a gravidez é uma das etapas da vida onde ocorrem diversas modificações, tanto biológicas como sociais na vida da mulher e que refletem em seu corpo, em seus sentimentos e no novo papel social a ser desempenhado. Por conseqüência, a gestação consiste em um período em que a sensibilidade encontra-se exacerbada, tornando-se mais suscetível às emoções diante dos problemas cotidianos e tendo às vezes mais dificuldades em utilizar seus mecanismos de defesa (MALDONADO, 1997).

A gestação, considerada sócio-historicamente um período de clímax da feminilidade, representa também o poder de dar a vida. Entretanto, com o surgimento da epidemia da AIDS transforma-se em um problema de morbimortalidade relacionado à saúde reprodutiva.

O período gestacional é um dos momentos em que a mulher efetivamente procura os serviços de saúde, sendo de extrema relevância realizar uma avaliação mais ampliada e integral sobre os aspectos que envolvem a saúde dela. Com o advendo da 
AIDS e da possibilidade de transmissão vertical, o pré-natal tornou-se um dos momentos de rastreamento em mulheres da soropositividade.

A Política Nacional de Atenção Integral a Saúde da Mulher (BRASIL, 2004) preconiza um cuidado diferenciado, humanizado desde o momento do atendimento prénatal até o puerpério. Nessas ações de saúde, se evidencia o papel do enfermeiro na promoção da saúde e prevenção de doenças com base em ações educativas e assistenciais (PENNA ET AL, 2006).

Uma das ações do enfermeiro no atendimento à gestante inclui o aconselhamento para sorodiagnóstico para HIV, seja dentro do atendimento pré-natal ou na maternidade. Se o exame positivar, a comunicação deverá ser feita com sensibilidade, humanização e acima de tudo, respeitando os direitos reprodutivos e humanos dessa clientela a partir das questões de gênero e sexualidade (BRASIL, 2006).

Mas, observamos que a temática é pouco abordada dentro dos cursos de graduação em Enfermagem e que os protocolos existentes não abordam os aspectos psíquicos e emocionais que envolvem a comunicação do resultado. Podemos constatar tal fato nos próprios documentos do Ministério da Saúde sobre o atendimento no Prénatal e Prevenção e Tratamento da Transmissão Vertical (Brasil, 2000) onde é apontada uma prescrição de condutas a serem adotadas no cuidar de gestantes com resultado de HIV positivo, sem evidenciar a realidade do profissional de saúde e as dificuldades enfrentadas por ele.

A gestante soropositiva deve ser uma preocupação para os profissionais de saúde, em particular para enfermeira obstétrica que atende à mulher durante o período gestacional e no momento do parto e puerpério. Dessa forma, observamos a realidade de algumas enfermeiras obstétricas a partir de sua vivência ao comunicar um resultado positivo para HIV, no atendimento direto às gestantes matriculadas em serviços de prénatal ou internadas em maternidades da rede básica de saúde.

Buscando aprofundarmos sobre a temática da comunicação sigilosa e do sorodiagnóstico da AIDS almejamos com esta pesquisa alcançar os seguintes objetivos: Identificar os sentimentos dessa enfermeira em relação à cliente e à comunicação do resultado positivo de exame sorológico para HIV; Descrever as estratégias utilizadas pela mesma para comunicação do resultado positivo à gestante. 


\section{REVISÃO DE LITERATURA}

\section{Epidemia de AIDS no Brasil: características dos anos 80 até a atualidade}

No início da década de 80, a Síndrome da Imunodeficiência Adquirida (Aids) era considerada como uma doença restrita a determinados grupos ditos de risco, entre eles os homossexuais, as pessoas que recebiam doação de sangue, hemofílicos e usuários de drogas injetáveis. Estando presente principalmente envolvendo homens, de classe média, e habitante das grandes metrópoles (BRASIL, 2003).

Com a evolução desta doença novos casos surgiram, constatando-se a penetração do vírus em diversos segmentos sociais e a mudança do perfil do portador do HIV. A Aids passou a se apresentar mais efetivamente nos grupos heterossexuais, e hoje se observa um maior número de mulheres contaminadas. Dados epidemiológicos reportam um aumento de quase $80 \%$ no número de notificações de mulheres que adquiriram HIV; em relação aos homens, este percentual não chega aos vinte por cento (BRASIL, 2003). A proporção de mulheres portadoras do vírus chega ao índice de um caso de AIDS em mulher para cada 1,7 caso em homem (GALVÃO, 2003).

Além da mudança no perfil sexual da epidemia, hoje se firma a pauperização e interiorização da mesma. Observa-se que a doença passa a se expandir nas pequenas e médias cidades, destaca-se um maior aumento da taxa de incidência em cidades com menos de cinqüienta mil habitantes, ou seja, está ocorrendo à estabilização da taxa de incidência nas grandes metrópoles (BRASIL, 2003).

Isto nos leva a afirmar que a crescente interiorização vem acompanhada da entrada da doença em camadas mais pobres da população, cujo acesso à informação e aos meios de proteção é limitado. Um indicador de pauperização é o tempo (em anos) de estudo das pessoas que adquirem o vírus HIV. Em 1983, 25 \% encontravam-se no ensino fundamental, já em 1993 este índice chegava a 70 \% (BACON, 2004).

Portanto, a característica da epidemia se modificou ao longo das décadas. Podese afirmar que, atualmente, a SIDA encontra-se mais frequiente em cidades de médio e pequeno porte e na população de baixa renda. Também há um aumento proporcional em heterossexuais, enfatizando o crescimento da contaminação de mulheres, fazendo com que a razão entre os sexos fiquem equivalentes. Assim, não há mais um grupo de risco para essa doença e sim uma situação social que torna as pessoas vulneráveis e aumenta a probabilidade de se adquirir o vírus (BRASIL, 2003). 


\section{Feminilização da AIDS uma questão de gênero}

O conceito de gênero aborda as características determinadas pela construção social e histórica que são consideradas de um fenótipo sexual, ou seja, o masculino e o feminino. Contudo, quando abordamos a questão de gênero e AIDS lembramo-nos de submissão social que reflete no comportamento sexual. Ao longo da história a mulher esteve subjugada ao gênero masculino, não tendo seus direitos humanos respeitados e nem mesmo sendo detentora de seu próprio corpo, passava da submissão paterna para a marital nos ambientes domésticos; e no ambiente público sempre foi considerada com profissional de menor potencial que o sexo masculino.

Apesar de esta realidade está aparentemente distante dos dias atuais, em uma visão mais minuciosa percebemos esses valores enraizados em nossa sociedade. E isto reflete diretamente na questão da sexualidade e direito da mulher, que hoje, relaciona-se à epidemia de SIDA e as altas taxas de mulheres contaminadas por transmissão sexual de seus parceiros.

A mulher tem uma maior dificuldade em se prevenir da AIDS e de outras DSTs por apresentar barreiras para negociar o uso de preservativo com o parceiro. O uso do preservativo transcende o assunto em si e adentra nas complexas representações sociais que envolvem o relacionamento entre homem e mulher, nestas em que há oposição de uma cultura positiva da masculinidade, perante a uma cultura feminina marcada pelo silêncio, conformismo e pelo ocultamento. Em suma: as questões de gênero e as relações de poder dificultam a prevenção da AIDS e aumentam o risco de transmissão às mulheres (PAIVA, 2000).

\section{Políticas públicas para a Saúde da Mulher e AIDS}

Em decorrência do avanço da epidemia de AIDS entre as mulheres, o governo brasileiro passou a ter um olhar diferenciado para este fato. A partir de então passou a elaborar estratégias e diretrizes de prevenção e planos para prestar uma assistência adequada à mulher HIV positiva.

Um dos pontos de partida para elaboração da Política Nacional de Assistência a mulher HIV+, foi o Programa de Assistência Integral a Saúde da Mulher - PAISM - de 1984 (BRASIL, 2003). Este aborda uma visão mais completa da saúde feminina, em que as necessidades psicológicas, emocionais e sociais relacionadas à mulher devem ser vistas e atendidas. Isto leva a uma nova concepção de assistência baseada na 
integralidade, e que hoje é uma característica marcante do cuidar em saúde e que norteia a política nacional de combate a SIDA.

Assim, a Política Nacional de Assistência à mulher soropositiva para o vírus HIV (BRASIL, 2003) executa ações nas seguintes áreas: aconselhamento individual e coletivo nos serviços de saúde que prestam assistência a mulher, principalmente os serviços de planejamento familiar, pré-natal, ginecologia, centros de testagem anti-HIV e outras DSTs e maternidade, no atendimento à mulher vítima de violência, investimento em insumos de prevenção, como preservativos masculinos e femininos e campanhas educativas em meios de comunicação populares.

Também, através da Portaria nº 2104/ 2002, o Ministério da Saúde implementou normas para diminuir a transmissão vertical do vírus HIV e ampliar a testagem de gestantes para sorodiagnóstico. Como medidas implementaram-se a testagem de cem por cento das parturientes após o Aconselhamento nas maternidades, garantir o acesso as medicações profiláticas aos recém-nascidos de mães soropositivas até os seis meses de idade, o tratamento/ acompanhamento para as portadoras do vírus, incluindo orientações sobre os riscos da amamentação, oferecimento de medicações que inibam a lactação e enfaixamento das mamas.

\section{AIDS e Gestação: a possibilidade da transmissão vertical}

A transmissão vertical tem sido uma grande preocupação, devido ao aumento do número de gestantes que são portadoras do vírus HIV. A transmissão vertical do HIV ocorre através da passagem do vírus da mãe para o bebê durante a gestação, o trabalho de parto, o parto propriamente dito (contato com as secreções cérvico-vaginais e sangue materno) ou a amamentação, sendo que cerca de 35\% dessa transmissão ocorre durante a gestação, $65 \%$ ocorre no peri-parto e há um risco acrescido de transmissão através da amamentação entre 7\% e 22\% por exposição (mamada) (BRASIL, 2006).

A fim de prevenir a transmissão vertical, investiu-se nas medidas de detecção como o teste rápido e o exame realizado na consulta pré-natal. E, também em gestantes HIV positivas usa-se a quimioprofilaxia com AZT injetável, AZT oral para o recémnascido durante as primeiras seis semanas de vida, avalia-se a forma em que acontecerá o parto de acordo com a carga viral (mais que 1000 cópias de vírus/ $\mathrm{ml}$ recomenda-se o parto cesáreo) e se recomenda a não amamentação (BRASIL, 2006).

A efetividade da prevenção da transmissão vertical está no Aconselhamento, que tem seu alcance a partir do estabelecimento de uma relação interpessoal entre 
profissional e cliente. O Aconselhamento é um diálogo baseado na relação de confiança que visa proporcionar às pessoas condições para que avaliem seus próprios riscos, tomem decisões e encontrem maneiras realistas de enfrentar seus problemas relacionados à DST e AIDS (BRASIL, 2006).

O aconselhamento é uma estratégia criada pelo Ministério da Saúde pra incentivar aos clientes que vão as unidades de saúde a detectarem precocemente problemas que envolvem DST/AIDS e a iniciarem o uso dos métodos preventivos. Neste processo o profissional de saúde deve ouvir as preocupações de cada pessoa atendida, esclarecer as dúvidas, incentivar o autocuidado, prover informações sobre modos de transmissão, sintomas e tratamentos de DST's e dar apoio emocional àqueles que necessitem.

O aconselhamento também está presente na consulta de pré-natal, onde se procura incentivar a gestante a realização dos testes para detectar as doenças sexualmente transmissíveis que põem em risco a sua saúde e a do bebê. Um destes constitui a sorologia para HIV (BRASIL, 2006).

\section{O cuidar de gestante HIV soropositiva}

A gestação é um período de expectativas diante do surgimento de uma nova vida, onde não se espera o advir de um agravo à saúde. Logo, quando esta surge tornase um momento delicado tanto para o profissional quanto para a gestante, principalmente quando a intercorrência é a descoberta de um estigma social de letalidade.

A sorologia HIV positiva é de impacto tanto para o enfermeiro que recebe o resultado e o comunica, quanto para a gestante. A AIDS trás consigo todo sentimento de morte e de irreversibilidade, sendo uma patologia envolvida em um mundo de preconceito e discriminação.

Para a mulher surgem sentimentos relacionados à vida e morte, e até mesmo surge o desejo de morrer, a preocupação com a gestação e a culpa pela possibilidade de transmitir a doença ao filho ou ao parceiro (PAIVA, 2000).

Neste momento, ao constatar um resultado de soropositividade para HIV em uma gestante, surgem três focos para o profissional: a preocupação com a saúde da mãe, a do bebê e a do parceiro desta gestante. Cabe ao enfermeiro prestar o apoio emocional necessário e contar com outros membros da equipe de saúde para prestar uma melhor 
assistência a essa mulher. Ainda, encaminhar ao pré-natal de alto risco para que desde o início ela possa começar a ser tratada, e o mais importante é informar sobre a possibilidade do tratamento e da manutenção de uma vida normal para ela e para o bebê que não necessariamente será portador do vírus e necessita de cuidado para nascer saudável. Assim, o profissional deve: acolher, orientar e cuidar desta cliente com todo zelo abstendo-se de julgamentos e preconceitos.

\section{METODOLOGIA}

Caracteriza-se por ser um estudo descritivo, exploratório, desenvolvido a partir de uma abordagem qualitativa. O caráter exploratório da pesquisa busca identificar aspectos mais amplos relacionados à comunicação sigilosa do resultado do sorodiagnóstico da AIDS, identificando a forma como a enfermeira obstétrica irá vivenciar este evento.

Os dados foram coletados através de questionários contendo perguntas abertas: Você traçou alguma(s) estratégia(s) para a comunicação do resultado? Como você elaborou a(s) estratégia(s) e quais foram elas? De que forma foi comunicado o resultado a gestante? Quais as sensações relacionadas à entrega deste resultado a essa cliente no momento em que antecedeu a consulta e na hora em que você estava frente a frente com a mesma? O período de coleta de dados abrangeu os meses de janeiro e fevereiro de 2008.

Os sujeitos da pesquisa foram dez enfermeiras obstétricas que se encontram matriculadas no curso de especialização em enfermagem obstétrica e/ou docentes da Faculdade de Enfermagem da UERJ. A pesquisa encontra-se em consonância com as normas e princípios éticos do Conselho Nacional de Pesquisas em Seres Humanos (Resolução 196/96), que foi aprovada pelo Comitê de Ética e Pesquisa da UERJ sob o parecer 055/2007 protocolado pelo número 021.3.2007 em 10 de Setembro de 2007.

A análise dos dados foi feita à luz do referencial utilizando a técnica de análise de conteúdo, que é definida como um conjunto de técnicas de análise de comunicação visando obter, por procedimentos sistemáticos e objetivos de descrição de conteúdos das mensagens, indicadores que permitam a inferência de conhecimentos relativos às condições de produção/recepção destas mensagens (BARDIN, 2000). 
Com a organização e análise dos dados algumas categorias emergiram compondo nossos resultados: 1) Condutas de enfermagem diante do resultado soropositivo HIV, a qual foi subdividida em subcategorias - Condutas técnicas de enfermagem, Condutas relativas ao significado do resultado do teste e Condutas relativas ao benefício do tratamento; 2) Estratégias para comunicar o resultado de soropositividade HIV, que foi subdividida em Estratégias a partir da política de humanização da assistência, Estratégias de cuidar com base na comunicação e nas informações sobre a doença e Estratégias referentes à presença do acompanhante; 3) Sentimentos e Emoções da enfermeira obstétrica ao apresentar o resultado, na qual emergiram as subcategorias - Sentimentos pessoais ao comunicar o resultado; Dificuldades vivenciadas ao comunicar o resultado e Sentimentos determinantes à conduta profissional diante a comunicação do resultado.

\section{RESULTADOS}

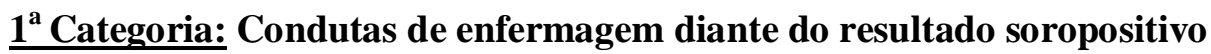

Caracteriza-se como a categoria com um pouco mais de expressividade em nosso estudo, aparecendo com um percentual de 35,9\%, ou seja, 29 unidades de registros (UR) e 16 unidades de significação. Nesta foram apontadas as atividades desenvolvidas pela enfermeira obstétrica à mulher soropositiva para HIV, em algum momento do ciclo gravídico-puerperal, por ocasião da comunicação do resultado.

Esta categoria, para melhor aprofundamento das temáticas surgidas foi subdividida nas seguintes subcategorias: Condutas técnicas de enfermagem, Condutas relativas ao significado do resultado do teste e Condutas relativas ao benefício do tratamento

A subcategoria "Condutas técnicas de enfermagem" recebeu esse nome por se tratar de cuidados prestados diretamente a cliente portadora do vírus HIV, não sendo avaliado, neste momento, o fato da cliente ser ou não gestante, ou seja, poderia ser parturiente ou puérpera.

Verificamos 13 URs englobando ações de encaminhamento, repetições de exames, orientações sobre o tratamento, orientações sobre os cuidados de prevenção quanto aos parceiros, entre outras.

Essas condutas relativas às ações das enfermeiras vão ao encontro das políticas de saúde vigentes hoje em nosso país, em especial no que toca a questões sobre 
atendimento integral. Na Lei $n^{\circ} 8080$ de 19/09/1990, temos que a integralidade da assistência é entendida como um conjunto articulado e continuo das ações e serviços preventivos e curativos, individuais e coletivos, exigidos para cada caso em todos os níveis de complexidade do sistema.

No Protocolo para Prevenção de Transmissão Vertical do HIV e Sífilis (BRASIL, 2006), com informações a respeito do aconselhamento pós-teste, é enfatizada a importância da utilização das informações já reveladas à cliente em momento $s$ anteriores, não esquecendo de complementar as informações sobre a pratica sexual, uso de álcool e outras drogas, elencando-se o mínimo de informações necessárias para contextualizar as orientações sobre medidas de controle e redução da vulnerabilidade e dos riscos.

Geralmente, os profissionais de saúde que já trabalham com a demanda de assistência a DST e HIV/AIDS têm a oportunidade ímpar de manter um contato direto com a intimidade da vida do cliente, podendo assim promover um trabalho preventivo ajustado às necessidades individuais.

Ainda, no contexto dos serviços de saúde onde costumam se apresentar tais situações, tanto os profissionais quanto os clientes são sujeitos suscetíveis ás vivências ditas conflituosas em função da complexidade da temática que tanto envolve questões relativas à sexualidade, poder, gênero, vida e morte. E o aconselhamento é um instrumento importante para a quebra da cadeia de transmissão das DST e HIV/AIDS na medida em que propicia uma reflexão sobre os riscos de infecção e a necessidade de sua prevenção.

No processo de aconselhamento o profissional de saúde é principal ator e é quem deve atuar de forma a incentivar o cliente a se cuidar e a se prevenir. Ele deve ouvir as preocupações de cada pessoa atendida, esclarecer as dúvidas, incentivar o autocuidado, prover informações sobre modos de transmissão, sintomas e tratamentos de DSTs e dar apoio emocional àqueles que necessitem. Em particular com gestantes, essas enfermeiras demonstram um cuidar mais minucioso e delicado, haja vista que está sendo gerada uma vida" (BRASIL, 2006).

Abaixo destacamos algumas falas das entrevistadas:

"[...] recapitulo as informações dadas anteriormente e fornecendo as possibilidades de acompanhamento, tratamento e perspectivas." Enf 06

"Em primeiro lugar queria ouví-la porém a mesma permaneceu em silêncio por alguns minutos e chorou." Enf 05 
"[...] conversei com a gestante e seu companheiro, esclarecendo a importância dele realizar o teste para o anti-HIV e ela realizar o tratamento" Enf ${ }^{a} 03$

De acordo com esses relatos notamos também, que as ações das enfermeiras obstétricas entrevistadas são realizadas de forma a atender as diretrizes da assistência preconizada pela política pública de saúde. E além da comunicação do resultado, elas também se preocupam em estar ouvindo e acolhendo essa gestante em suas demandas e dificuldades, atentando para o fato da AIDS ser uma doença crônica, de difícil compreensão, que pode gerar revolta e desespero. Nesse momento tão difícil, deve-se enfatizar as possibilidades de tratamento.

A subcategoria seguinte representa as condutas de enfermagem indicadas pelas enfermeiras obstétricas relativas ao significado do resultado do teste, as quais são apresentadas através de 11 URs.

Nessa subcategoria temos dados relativos à comunicação do resultado sorológico positivo para HIV propriamente dito, onde as profissionais enfermeiras prestam orientações relativas à realização do teste, ou seja, realizando um aconselhamento pré-testagem, explicando como o exame é realizado, as questões éticas envolvidas, possíveis dúvidas sobre o processo e também orientações após a testagem, na entrega do resultado propriamente dito, orientando sobre o tratamento e prevenção do bebê.

Nesse momento, a profissional enfermeira obstétrica esclarecerá acerca de questionamentos, expectativas, dúvidas e anseios exercendo o papel de cuidadora e educadora, auxiliando inclusive na apropriação dessa mulher sobre seu corpo, na formação de opinião e de enfrentamento às questões referentes ao sorodiagnóstico positivo para o HIV/AIDS. Tais atividades se enquadram nas competências e atribuições da enfermeira, segundo a nova Lei das Diretrizes Curriculares de Enfermagem e dos princípios do atendimento no Sistema Único de Saúde.

A Lei $n^{\circ} 94.406$ de 08/06/1987, diz no Art. $8^{\circ}$, alínea M que o enfermeiro como parte integrante da equipe de saúde deve participar em programas e atividades de educação sanitária, visando à melhoria de saúde do individuo, na família e da população em geral.

"Não pude traçar estratégias para contar, só pude dar apoio e as orientações que a gestante solicitou." Enf" 07 
"Busco discutir e explorar todas as dúvidas e encaminhar para os procedimentos posteriores." Enf ${ }^{a} 09$

No Protocolo para a Prevenção de Transmissão Vertical de HIV e Sífilis (BRASIL, 2006), no capítulo referente ao aconselhamento pós-teste, preconiza-se que em caso de resultado HIV positivo que o profissional esteja preparado para oferecer apoio emocional, respeitando o tempo da gestante, bem como a reação ao resultado. Informações sobre o significado do resultado, as possibilidades de tratamento para a gestante e a possibilidade de evitar a infecção de seu bebe, encaminhamentos necessários e discussão sobre as medidas de prevenção a serem adotadas, devem ser oferecidas e abordadas de acordo com a condição emocional das gestantes.

Vale ressaltar a necessidade de orientação e monitoramento constantes, em situações que seja necessário a utilização de medicação pela gestante para a prevenção da transmissão vertical durante a gravidez, mesmo sem apresentar a doença pode gerar muitas dúvidas nessa mulher.

Notamos, portanto, que as profissionais têm sedimentado em seu saber e fazer científico em estratégias de acolhimento essenciais para o bom atendimento e acompanhamento dessa cliente soropositiva para HIV/AIDS. Nesse momento delicado que é o processo gestacional, onde inúmeras expectativas, dúvidas, transformações de identidades sociais (a mulher deixa de ser filha para ser mãe) e conseqüentemente diversas emoções e sentimentos envolvidos são de grande importância um atendimento que valorize o acolhimento, a escuta sensível, a humanização do cuidar dessas mulheres e sua família.

$\mathrm{Na}$ subcategoria em que são tratadas as condutas relativas aos benefícios do tratamento, com 6,2\% das unidades estudadas, as orientações prestadas são exclusivamente realizadas atentando para a adesão ao tratamento e a importância do mesmo.

Percebe-se através dos depoimentos das entrevistadas que essas orientações são realizadas com o intuito de estimular a gestante a iniciar, quando previsto, e manter o tratamento preconizado.

As orientações geralmente incluem questões a respeito da cronicidade da doença, sua relação com o parceiro e seu filho, mas enfatiza também, a possibilidade de manter-se bem à medida que o tratamento seja seguido. 
"[...] importância do tratamento para ela [...] e a possibilidade de manter-se bem a medida em que ela faça o tratamento." Enf ${ }^{a} 03$

Essas orientações são de grande importância, pois neste momento muitos sentimentos surgirão durante o processo gestacional, tais como: idéias quanto ao preconceito que poderá vivenciar; mudanças no convívio com a família, entre outras situações. Por esses motivos, é necessário que a enfermeira ofereça condições à gestante de adquirir consciência sobre o resultado e passe a entender e aceitar o diagnóstico, auxiliando na obtenção de um melhor resultado do tratamento instituído.

Reiteramos desta forma, a importância da orientação e estimulação da adesão ao tratamento para que ocorra um efeito satisfatório e um posterior controle da patologia, melhor conhecimento sobre a terapêutica e conseqüentemente segurança quanto a ações de prevenção para a cliente em questão e para parceiro.

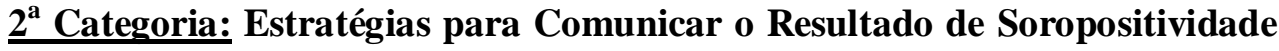
para o vírus do HIV

Esta segunda categoria que emergiu em nosso estudo engloba 30,8\% das unidades de significação do estudo. Esta categoria também para maior aprofundamento foi subdivida em outras três subcategorias: "Estratégias a partir da política de humanização da assistência", "Estratégias de cuidar com base na comunicação" e nas informações sobre a doença e "Estratégias referentes à presença do acompanhante".

Na primeira subcategoria - Estratégias a partir da política de humanização da assistência foram descritas as estratégias utilizadas pelas enfermeiras para estar realizando a comunicação do resultado soropositivo para HIV a gestante atendida, onde contamos com informações que nos remete as políticas públicas instituídas em nosso país para o aconselhamento a clientes portadoras de HIV/AIDS, referentes à humanização da assistência. Essa subcategoria é responsável por 10 URs, alcançando $12,3 \%$ do total de unidades de significação.

Os mecanismos de comunicação presentes nas falas das entrevistadas são baseados no acolhimento, escuta e cuidar sensível, visando à criação de um laço de afetividade com a cliente para que a mesma sinta-se à vontade e amparada pelo profissional, vendo nele uma pessoa em quem pode contar e buscar ajuda em um momento tão difícil, que é a descoberta de uma doença crônica e tão estigmatizada pela sociedade. A partir disso, é muito importante que o profissional que esteja atendendo 
essa gestante utilize o bom senso e sensibilidade para compreender o momento em que deve avançar com as orientações ou apenas amparar e ouvir essa cliente.

Com base nestas informações, consideramos que o profissional encarregado de prestar esse atendimento, a comunicação do resultado e o aconselhamento dessa gestante, deve estar capacitado, pois apenas uma expressão facial diferente pode comunicar e revelar muitas informações. É necessário também que o profissional compreenda o seu papel de cuidador inclusive durante a comunicação desse resultado no sentido de que essa cliente sinta-se de fato acolhida e cuidada e não abandone o tratamento.

Entendemos aconselhamento como um processo de escuta ativa, individualizado e centrado no cliente. Pressupõe a capacidade de estabelecer uma relação de confiança entre os interlocutores, visando ao resgate dos recursos internos do cliente para que ele mesmo tenha possibilidade de reconhecer-se como sujeito de sua própria saúde e transformação.

Vale ressaltar que a testagem para HIV é de caráter voluntário e anônimo, onde somente após assinatura de um termo de compromisso aceitando a testagem, é permitida a realização do teste. Com isso é necessário que se priorize a individualidade e a privacidade da cliente, pois sendo a gestante a figura principal do processo é necessário focar a estratégias o cuidar na pessoa com suas peculiaridades.

"[Procuro] Criar um laço de afetividade e co-participação na consulta de pré-natal, demonstrar um cuidar sensivel...." Enf 02

"[...] apenas utilizei o bom senso e a sensibilidade a partir da abertura que esta cliente se fez disponível." Enf ${ }^{a} 08$

Essas estratégias utilizadas pelas enfermeiras obstétricas levam em consideração a bagagem profissional das mesmas. Na maioria das vezes não é necessário precisamos pensar para agir. Grande parte das práticas do dia-a-dia, inclusive os comportamentos referente à saúde, obedece a uma lógica, em geral, não consciente ou planejada (MONTEIRO, 2002).

$\mathrm{Na}$ segunda subcategoria, apontamos as Estratégias de cuidar com base na comunicação e informações sobre a doença, que é representada por 10 URs. Nesta, verificamos exclusivamente estratégias de comunicação da doença e informações a respeito da transmissão vertical, informações a respeito do teste. 
No momento da comunicação desse resultado é importante que o profissional perceba o momento em que a cliente - gestante, esteja disponível e acessível para receber a informação. Entendemos que após a comunicação do resultado, o ritmo da consulta será conduzido também a partir da própria cliente, onde a mesma, dentro de seus conhecimentos e limites emocionais tomará decisões sobre as providências a serem desenvolvidas durante todo o processo gestacional e de sua vida.

Com isso, visando eliminar as diferenças, o atendimento prestado deve ser embasado na comunicação e no respeito aos direitos humanos e de saúde reprodutiva, para que não haja ruídos e perda de informações importantes no decorrer do atendimento.

Os especialistas em comunicação afirmam que $70 \%$ de toda comunicação é não-verbal. Geralmente podemos escolher as palavras que vamos emitir, mas dificilmente podemos controlar as respostas não-verbais que traduzem a verdade (SILVA, 2004).

"[...] qual as conseqüências para o RN no caso de contaminação materna e comunicar o resultado após perceber que a mulher compreendia o problema em questão." Enf ${ }^{u} 07$

"O resultado deve ser dado sem rodeios e verificar como foi à compreensão do resultado pela pessoa, avaliar o que a gestante e a família pensa e o que eles estão sentido [...]" Enf 09

O tratamento do paciente com AIDS traz seqüelas que podem se tornar irreversíveis na vida da pessoa que presta serviço nesse contexto. As exigências conflitantes que envolvem simultaneamente responsabilidade e auto-preservação, o indivíduo se encontra diante de situações ambivalentes que necessitam ser esclarecidas (FIGUEIREDO E FIORONI, 1996).

$\mathrm{Na}$ terceira subcategoria - Estratégias referentes à presença do acompanhante verificou-se que apesar de numericamente pouco expressiva, apenas 4 URs, apresenta uma significação infinita no atendimento ao paciente HIV positivo e gestante.

Atualmente existem legislações e políticas de atendimento a mulher gestante onde é preconizada a presença de um acompanhante escolhido por ela, nas consultas de pré-natal e até mesmo na hora do parto, uma dessas políticas é a LEI ${ }^{\circ} 11.108$, Portaria GM/MS n 2.418 de 2005.

As enfermeiras apontam que a mulher escolherá se o acompanhante vai estar com ela na sala ou se este aguardará do lado de fora e até mesmo se ele comparecerá, pois a presença do acompanhante depende do desejo da mulher.

"Utilizando sempre o acolhimento e a verdade, mas também solicitando um acompanhante, caso ela aceitasse, mesmo que ele aguardasse lá fora do consultório." Enf ${ }^{a} 02$ 
Ao descobrir-se soropositivo para o HIV, imagina-se que a figura do cuidador tem um papel essencial, visto que toda a rede de relacionamento e suporte se desfaz e precisa ser reconstruída para ajudá-lo no enfrentamento da doença. Paiva, (2001) destaca a dificuldade de aceitação da família no cuidado de um portador, devido ao medo do contágio, dificuldades financeiras, falta de informação da doença e as alusões moralistas em relação à identidade sexual e sexualidade e uso de drogas.

Os significados que a cultura atribui à doença podem influenciar as reações da família em relação ao indivíduo soropositivo para o HIV/Aids, passando inclusive a discriminá-lo e excluí-lo do grupo familiar. Neste contexto de doença, SOUSA, KANTORSKI E BIELEMANN (2004) afirmam que cada família possui uma movimentação singular, interpretando a situação de acordo com sua cultura, código e regras o que traz implicações para o seu comportamento e comunicação entre os membros.

Observa-se, portanto, a importância de uma rede de apoio junto a essa cliente no momento da consulta, mas principalmente no ambiente familiar, a ajudando, amparando e tratando sem medos e preconceitos.

\section{$\underline{3^{a} \text { Categoria: Emoções e Sentimentos da enfermeira obstétrica ao }}$ apresentar o Resultado Soropositivo HIV}

Esta última categoria emergiu dos depoimentos das enfermeiras obstétricas ao relatar sobre as emoções vivenciadas no momento de entrega do resultado de sorodiagnóstico positivo para HIV às gestantes. Verificamos que ao comunicar tal resultado à mulher, durante o período do ciclo gravídico, muitas são as sensações sentidas por essas profissionais.

Nesta categoria que abrange $33,3 \%$ do total de URs do estudo, os resultados que dizem respeito aos sentimentos e emoções também foram divididos em três subcategorias para melhor visualização da discussão, que são as seguintes: "Sentimentos pessoais ao comunicar o resultado", "Dificuldades vivenciados ao comunicar o resultado", "Sentimentos determinantes à conduta profissional diante a comunicação do resultado", respectivamente.

Na primeira subcategoria, os sentimentos aflorados são os de cunho pessoal, que a enfermeira vivencia sem ver a cliente de modo impessoal, e sim a ver com alguém próximo, familiar. Nesta subcategoria temos 19,7\% das URs, ou seja, 16 URs. 
O ser humano é dotado em sua essência de sentimentos e emoções, o que o torna sensível ao sofrimento alheio. Geralmente, o profissional enfermeiro sente-se ainda mais desafiado, porque é ele que estará no papel de cuidador da pessoa que sofre. $\mathrm{O}$ ato de cuidar do outro envolve atenção, responsabilidade, respeito, limite e até mesmo o medo; é a compreensão do outro em sua totalidade. Mas antes de cuidar do paciente, os enfermeiros necessitam compreender a si próprios e suas necessidades.

\section{"[...] mas também medo do resultado ser falso e ter que dizer que é positivo”. Enf" 02}

"Quando a cliente me questionou sobre o resultado senti um nó na garganta, não sabia o que responder" Enf ${ }^{a} 04$.

Os objetivos de um relacionamento terapêutico devem ser direcionados no sentido do crescimento do cliente e incluem questões como Auto-realização, autoaceitação, e auto-respeito aumentados, senso claro de identidade pessoal e da integração pessoal melhorada, capacidade de formar relacionamentos íntimos, interdependentes e interpessoais com capacidade de dar e receber amor, melhoria da função e capacidade aumentada de satisfazer as necessidades e alcançar objetivos pessoais realistas (STUART \& LARAIA, 2002).

$\mathrm{Na}$ segunda subcategoria onde temos o registro de 06 URs emergiram nos depoimentos as dificuldades vivenciadas pelas enfermeiras obstétricas ao comunicar o resultado ficando visíveis os sentimentos e emoções vivenciadas por esse profissional quando se depara com a necessidade de comunicar um resultado sorológico para HIV+.

Questões como a dificuldade de falar e a desestruturação emocional do profissional ao se deparar com a necessidade de comunicação do resultado positivo são emoções muito presentes no discurso. Tal fato possivelmente se deve a relação sóciohistórica da doença da AIDS e a letalidade. Quando o cuidado tem por constante a possibilidade da morte próxima requer do profissional e mesmo do indivíduo um suporte que necessita ser desenvolvido.

SILVEIRA E LUNARDI (2001) ressaltam o papel grandioso e enriquecedor da enfermeira ao lidar com a morte iminente e afirmam que: "Ser enfermeira cuidadora de quem vivencia o processo de morrer é poder viver diariamente esse desafio, junto com os pacientes e seus familiares; é cuidar humanamente, é observar constantemente, é estar atenta ao seu nível de consciência, coloração, sinais vitais, características da pele, à necessidade de realizar procedimentos, mas mais do que isso é a possibilidade de 'ser presença' junto ao paciente. 
Entendemos que a habilidade e a competência são fundamentais para compreender a experiência de cuidar, o que requer ser receptiva e estar atenta aos estímulos transmitidos pelos pacientes, mesmo que seja um caminho de incertezas e expectativas, deixando 'aflorar a sensibilidade e a intuição para que possa adentrar no mundo dos clientes, ouvindo-os, olhando-os, envolvendo-os de uma maneira empática, procurando compreendê-los. Entretanto, é necessário que a formação da profissional seja direcionada também para essas questões e temáticas. É importante que a pessoa que realiza o aconselhamento tenha conhecimentos atualizados sobre DST e HIV/aids e, em especial, disponibilidade para: reconhecer suas próprias limitações e potencialidades; valorizar o que o cliente sabe, pensa e sente; perceber as necessidades do cliente e dar respostas a estas, e respeitar a singularidade do cliente (BRASIL, 2006).

"O ato de notificar o resultado nos coloca em uma situação muito difícil [...] tudo isso e outros sentimentos que se traduzem e provocam uma desordem emocional tanto para ela como para quem deu o resultado[...]." Enfag

"Foi o teste rápido realizado na maternidade, no momento da chegada ao pré-parto. Isto se torna mais complicado para o profissional [...] mobiliza muito as emoções da mulher e do profissional de saúde." Enf ${ }^{a} 10$

Na última subcategoria presente no estudo foi a de "Sentimentos determinantes à conduta profissional diante a comunicação do resultado". Nesta, temos a concentração de 6,2\% das URs do estudo, que apesar de pouco expressiva numericamente, representa muito social e profissionalmente. Nesta subcategoria emerge sentimentos de empatia, vontade de estar ajudando a cliente em suas necessidades e o medo da evasão da cliente do serviço, mostrando a preocupação do profissional com a sua responsabilidade junto à gestante para o cuidado, acompanhamento e orientação.

O relacionamento terapêutico entre enfermeira e paciente é uma experiência de aprendizado mútuo e uma experiência emocional corretiva para o paciente. Nessa relação, a enfermeira utiliza a si próprio e as técnicas clinicas especificadas na trabalho com o paciente para gerar introvisão e alteração comportamental do paciente. (STUART \& LARAIA, 2002)

Verificamos que as enfermeiras sentem-se responsáveis pela saúde de suas clientes. Demonstram preocupação sobre sua vida e de seus bebês, receiam sobre o impacto do resultado em suas vidas, temendo inclusive o abandono do pré-natal.

“Expectativa quanto às reações da paciente, receio da evasão da cliente do pré-natal.” Enf $\boldsymbol{O N 2}^{2}$ 
Brasil (2006), diz que para compreender o caminho que as mulheres percorrem em direção à infecção por DSTs, é necessário aperfeiçoar a escuta e a abordagem dos profissionais de saúde a esse segmento, respeitando suas especificidades biológicas, psicossociais e culturais, e suas circunstancias de ser viver e sentir.

"Fiquei triste, pois cada resultado de uma DST ou de uma doença que não tem cura sempre me coloca no lugar da pessoa, pois vejo o quanto é difícil para a mulher negociar o uso do preservativo e de questões relacionadas a vida sexual que foi a via de contaminação." Enf"05

Essas percepções presentes no ser humano fazem com que ele muitas vezes sofra ao se depara com situações de dualidade como a vida e a morte. Para o profissional de saúde esta vivencia é muito maior, principalmente ao se tratar de pacientes com doenças crônicas, no caso em questão o HIV/IDS, sendo por isso de tão grande importância o treinamento desse profissional para que ele esteja preparado para realizar um acolhimento humanizado, demonstrando empatia, porém sem deixar que a emoção suplante o seu cuidar em saúde.

\section{CONSIDERAÇÕES FINAIS}

Não há dúvidas que a profissional enfrenta algum dilema ao comunicar o resultado de soropositividade para Hiv às gestantes, sendo comum, observar um impacto emocional. No enfrentamento a essas dificuldades, pode-se identificar o surgimento de sentimentos de ordem pessoal aflorados dentro da ação profissional de comunicar sobre o exame. Tal fato, nos leva a refletir sobre a importância do profissional em estar capacitado. Dessa forma é comum as profissionais estabelecerem estratégias ao comunicarem os resultados. Basicamente, as mesmas são realizadas com base nos protocolos do Ministério da Saúde: Acolhimento e a Política de Humanização. As mesmas também são influenciadas pela experiência profissional e o conhecimento teórico.

Consideramos assim, de grande relevância a necessidade de capacitações e atualizações dos profissionais de saúde, em particular a enfermeira acerca da comunicação e aconselhamento referente aos exames e resultados para HIV/AIDS

A conduta da enfermeira deve ser calcada no cuidar de forma humanizada e integral, sempre se preocupando em orientar e fazer com que a cliente e a familia esteja 
inserida no tratamento. Fato importante é a preocupação com a adesão do tratamento tanto para o beneficio da mulher quanto do bebê.

\section{REFERÊNCIAS}

BACON, Oliver. HIV/AIDS in Brazil. AIDS Policy Research Center, University of California San Francisco. 2004.

BARDIN, L. Análise de conteúdo. Lisboa: Edições 70, 2000. . Ministério da Saúde. Protocolo para a prevenção de transmissão vertical

de HIV e sífilis. Brasília: Secretaria de Vigilância em Saúde, Programa Nacional de DST e AIDS, 2006. Ministério da Saúde. Plano nacional de políticas para as mulheres Brasília: Secretaria especial de política para mulheres, 2004. . Ministério da Saúde. Políticas e diretrizes de prevenção das DST/AIDS entre mulheres - Brasília:Secretaria Executiva, Coordenação Nacional de DST e Aids, 2003.

FIGUEIREDO, M. A. C. \& FIORONI, L. N. Uma análise de crenças relacionadas com a Aids entre participantes em O.N.G.s. Rev. Estudos de Psicologia, [s.l.], , 1996. v. 2(1): $28-4$

GALVÃO, Instituto Patrícia - Comunicação e Mídia. Mulheres com HIV/ Aids elementos para a construção de direitos e qualidade de vida. Disponível em: http://www.patriciagalvao.org.br. Acesso em 20/12/2006.

MALDONADO, Maria Teresa. Psicologia da gravidez. 17 ed. São Paulo: Ed. Saraiva, 1997.

MONTEIRO, Simone. Qual a prevenção? Aids, sexualidade e gênero em uma favela carioca. Rio de janeiro: Editora Fiocruz, 2002.

PAIVA, Mirian Santos. Representações sociais de enfermeiras e mulheres soropositivas para o hiv sobre a relação gestação/ soropositividade. Disponível em: http://www.aidscongress.net/pdf/306.pdf. Acesso em 10/04/2007.

PENNA, L.H.G., CORREIA, L.M., SILVEIRA, A.C., SALGADO, A.P. Projeto de extensão universitária: a enfermagem obstétrica no atendimento pré-natal de baixo risco Rio de Janeiro: Rev Enferm UERJ, abr/jun; 14(2):253-9, 2006.

SILVA, Maria Júlia Paes da. Qual o tempo do cuidado? Humanizando os cuidados de enfermagem. São Paulo: Centro Universitário São Camilo: Loyola, 2004.

SILVEIRA, R.S.; LUNARDI, V.L. A enfermagem cuidando de quem vivencia o processo de morrer. Texto e Contexto Enfermagem, Florianópolis, v.10, n.3, p. 170185, set./dez. 2001.

SOUSA, A. S.; KANTORSKI, L. P. \& BIELEMANN, V. L. M. A Aids no interior da família: percepção, silêncio e segredo na convivência social. Rev. Acta Scientiarum. Healf Sciences, Maringá, 2004, v.26 (1): 1-9.

STUART, G.W \& LARAIA, M.T Enfermagem psiquiátricas 4 ed.. Rio de Janeiro: Reichmann \& Affonso editores 2002. 